\title{
Respons Pembentukan Kalus Daun Pegagan (Centella Asiatica (L.) Urb.) dengan Penambahan Naphtalene Acetic Acid dan Benzil Amino Purin secara In Vitro
}

\author{
Response Formation of Gotu Kola Leaf Callus (Centella Asiatica (L.) Urb.) \\ with Addition of Naphtalene Acetic Acid and Benzyl Amino Purin In Vitro \\ Nurhayati Anwar ${ }^{1}$, Mayta Novaliza Isda ${ }^{1^{*}}$ \\ IJurusan Biologi, Fakultas Matematika dan Ilmu Pengetahuan Alam, Universitas Riau \\ Bina Widya Km 12,5 Simpang Baru, Pekanbaru 28293, Riau, Indonesia \\ Email: maytaisda@yahoo.com, nurhayatianwar2@gmail.com \\ *Penulis Korespondensi
}

\begin{abstract}
Gotu kola (Centella asiatica (L.) Urb.) is a medicinal plant that contains chemical compounds as triterpenoids and saponins. The chemical compounds can be produced quickly using in vitro callus induction. This study aimed to determine the effect of the BAP single and combination of BAP and NAA, and determine the effective concentration of a BAP single and combination of BAP and NAA on callus induction of gotu kola leaf explant using in vitro method. This study used Complete Randomized Design (CRD) which consisted of nine treatments : control, $1 \mathrm{mg} / \mathrm{l}$ BAP, $2 \mathrm{mg} / \mathrm{l}$ BAP, $1 \mathrm{mg} / \mathrm{l}$ BAP + 0,1 mg/l NAA, 2 mg/l BAP + 0,1 mg/l NAA, $1 \mathrm{mg} / \mathrm{l} \mathrm{BAP} \mathrm{+} \mathrm{0,3} \mathrm{mg/l} \mathrm{NAA,} 2 \mathrm{mg} / \mathrm{l}$ BAP + 0,3 mg/l NAA, $1 \mathrm{mg} / \mathrm{l}$ BAP + 0,5 mg/l $\mathrm{NAA}$, and $2 \mathrm{mg} / \mathrm{l} \mathrm{BAP}+0,5 \mathrm{mg} / \mathrm{l} \mathrm{NAA}$ with five replication for each treatment. Data obtained from observation were analyzed descriptively. The results showed that the best concentration to stimulate callus growth of pegagan leaf explants was in the P5 treatment (1 mg / I BAP + $0.3 \mathrm{mg} / \mathrm{I}$ NAA) with a percentage of $100 \%$ callus formation characterized by green callus color, compact callus texture and callus growth is high (+++).
\end{abstract}

Keywords: Gotu Kola, Centella asiatica (L.) Urb., Callus culture, BAP, NAA

\begin{abstract}
Abstrak
Pegagan (Centella asiatica (L.) Urb.) merupakan tanaman berkhasiat obat yang mengandung berbagai bahan aktif seperti triterpenoid dan saponin. Bahan aktif tersebut dapat diproduksi dengan cepat menggunakan teknik induksi kalus secara in vitro. Penelitian ini bertujuan untuk mengetahui pengaruh penambahan BAP tunggal dan kombinasi BAP dan NAA, dan menentukan konsentrasi terbaik dari penambahan BAP tunggal dan kombinasi BAP dan NAA terhadap pembentukan kalus dari eksplan daun pegagan secara in vitro. Penelitian ini menggunakan Rancangan Acak Lengkap (RAL) yang terdiri atas 9 perlakuan, yaitu: kontrol, $1 \mathrm{mg} / \mathrm{l}$ BAP, $2 \mathrm{mg} / \mathrm{l}$ BAP, $1 \mathrm{mg} / \mathrm{l} \mathrm{BAP} \mathrm{+} \mathrm{0,1} \mathrm{mg/l}$ NAA, 2 mg/l BAP + 0,1 mg/l NAA, 1 mg/l BAP + 0,3 mg/l NAA, 2 mg/l BAP + 0,3 mg/l NAA, $1 \mathrm{mg} / \mathrm{l} \mathrm{BAP}+0,5 \mathrm{mg} / \mathrm{l} \mathrm{NAA}$, dan $2 \mathrm{mg} / \mathrm{l} \mathrm{BAP} \mathrm{+} \mathrm{0,5} \mathrm{mg/l} \mathrm{NAA)} \mathrm{dengan} 5$ kali pengulangan untuk setiap perlakuan. Data hasil pengamatan yang diperoleh dibahas secara deskriptif. Hasil penelitian menunjukkan bahwa Konsentrasi terbaik untuk memacu pertumbuhan kalus eksplan daun pegagan yakni pada perlakuan P5 (1 mg/l BAP + 0,3 mg/l NAA) dengan persentase terbentuk kalus $100 \%$ ditandai dengan warna kalus hijau, tekstur kalus kompak dan pertumbuhan kalus yang tinggi (+++).
\end{abstract}

Kata kunci: Pegagan, Centella asiatica (L.) Urb., Kultur Kalus, BAP, NAA

Diterima: 20 Januari 2020, disetujui: 8 Mei 2020

\section{Pendahuluan}

Pegagan, antanan atau Gotu kola (Centella asiatica (L.) Urb.) merupakan tumbuhan merambat menutupi tanah, tidak berbatang, tinggi tanaman antara $10-50 \mathrm{~cm}$, memiliki daun hijau bergerigi. Pegagan banyak mengandung berbagai bahan aktif. (Winarto \& Surbakti 2003). Sutardi (2016) menyatakan bahwa triterpenoid merupakan senyawa paling penting yang terkandung dalam tanaman 
pegagan. Triterpenoid berfungsi meningkatkan fungsi mental, memberi efek menenangkan dan memperlancar peredaran darah menuju otak. Kendala utama penggunaaan senyawa ini adalah bahan baku dari tanaman pegagan yang terbatas di alam. Salah satu alternatif untuk mengatasi kendala tersebut melalui perbanyakan tanaman dengan teknik kultur kalus.

Kalus merupakan sumber bahan tanam yang sangat penting dalam meregenerasi tanaman baru. Setiap selnya memiliki kemampuan membentuk tanaman baru. Oleh karena itu, dengan menginduksi kalus kebutuhan bibit dalam jumlah banyak dapat dicapai dalam waktu yang singkat (Wahyuningtiyas et al. 2014).

Menurut Roy et al. (1996), kesuksesan kultur in vitro termasuk kultur kalus tergantung dari jenis media, eksplan dan zat pengatur tumbuh yang digunakan. Fitrianti (2006) menyatakan bahwa Zat Pengatur Tumbuh yang sering digunakan untuk pembentukan kalus yaitu dari golongan auksin NAA dan sitokinin BAP.

Tujuan dilakukannya penelitian ini untuk mengetahui respons eksplan daun pegagan dalam pembentukan kalus terhadap penambahan BAP tunggal dan kombinasi BAP dan NAA pada media MS, dan untuk menentukan konsentrasi terbaik dari BAP tunggal dan kombinasi BAP dan NAA terhadap respons pembentukan kalus eksplan daun pegagan secara in vitro.

\section{Metode Penelitian}

\section{Bahan dan Alat}

Alat-alat yang digunakan pada penelitian ini adalah Laminar Air Flow (LAF), autoklaf, oven, hot plate, timbangan analitik, kompor gas, panci, botol kultur, gelas kimia, gelas ukur, pipet tetes, pipet volume, petridish, skalpel, pinset, batang pengaduk, dan $\mathrm{pH}$ meter.

Bahan-bahan yang digunakan pada penelitian ini adalah ekplan daun muda pegagan, media MS (Murashige and Skoog) instan, Zat Pengatur Tumbuh (ZPT) (NAA, $\mathrm{BAP})$, agar kemasan, gula, $\mathrm{KOH}, \mathrm{HCl}$, akuades, detergen, Dithane 3\%, bayclin 20\%, dan alkohol $70 \%$.

\section{Rancangan Penelitian}

Penelitian ini menggunakan rancangan penelitian berupa Rancangan Acak Lengkap (RAL) dengan 9 (sembilan) perlakuan yang diulang sebanyak 5 (lima) ulangan, sehingga didapatkan 45 unit percobaan. Adapun perlakuan yang digunakan yaitu: P0 : Kontrol (Tanpa penambahan zat pengatur tumbuh), P1 : 1,0 mg/L BAP, P2 : 2,0 mg/L BAP, P3 : 1,0 $\mathrm{mg} / \mathrm{L} \mathrm{BAP}+0,1 \mathrm{mg} / \mathrm{L}$ NAA, P4 : 2,0 mg/L $\mathrm{BAP}+0,1 \mathrm{mg} / \mathrm{L}$ NAA, P5 : 1,0 mg/L BAP + $0,3 \mathrm{mg} / \mathrm{L}$ NAA, P6 : 2,0 mg/L BAP + 0,3 $\mathrm{mg} / \mathrm{L}$ NAA, P7 : 1,0 mg/L BAP + 0,5 mg/L NAA, P8 : 2,0 mg/L BAP + 0,5 mg/L NAA.

\section{Prosedur Kerja}

Pelaksanaan penelitian ini diawali dengan sterilisasi alat yang akan digunakan, dilanjutkan dengan pembuatan media dengan penambahan BAP tunggal dan kombinasi BAP dan NAA. Kemudian, dilakukan sterilisasi dan penanaman eksplan, eksplan yang sudah ditanam disimpan di dalam ruang inkubasi dengan suhu $23-25^{\circ} \mathrm{C}$, dan dilakukan pemeliharaan dengan menyemprotkan alkohol $70 \%$ setiap hari. Parameter yang diamati yaitu persentase eksplan hidup, persentase pembentukan kalus, waktu muncul kalus, morfologi kalus dan pertumbuhan kalus. Data yang diperoleh dibahas secara deskriptif.

\section{Hasil dan Pembahasan}

\section{Persentase Eksplan Hidup}

Data pada Tabel 1 menunjukkan bahwa persentase hidup eksplan daun pegagan mencapai semua perlakuan yaitu100\% kecuali pada kontrol. Pada kontrol (P0) persentase eksplan hidup sebesar $0 \%$, dikarenakan eksplan mengalami pencoklatan dan mengakibatkan kematian pada eksplan. Kematian eksplan pada P0 (kontrol) terjadi pada akhir pengamatan (50 HST) yang ditandai dengan pencoklatan pada seluruh bagian permukaan eksplan (Gambar 1.b.). Hal ini disebabkan oleh tidak adanya penambahan zat pengatur tumbuh pada media kultur dan sebagai respons eksplan terhadap pelukaan yang diberikan sehingga eksplan menghasilkan senyawa fenol (Denish 2007). 
Tabel 1. Rata-rata Persentase Eksplan Hidup dan Pembentukan Kalus pada Eksplan Daun Pegagan (Centella asiatica) dengan Perlakuan BAP Tunggal dan Kombinasi BAP dan NAA selama 50 HST

\begin{tabular}{|c|c|c|c|c|}
\hline \multirow{2}{*}{ Kode } & \multicolumn{2}{|c|}{ Perlakuan } & \multirow{2}{*}{$\begin{array}{l}\text { Rata-rata Persentase } \\
\text { Eksplan Hidup (\%) }\end{array}$} & \multirow{2}{*}{$\begin{array}{c}\text { Rata-rata Persentase } \\
\text { Pembentukan Kalus (\%) }\end{array}$} \\
\hline & BAP (mg/l) & NAA $(\mathbf{m g} / \mathbf{l})$ & & \\
\hline $\mathrm{P} 0$ & 0 & 0 & 0 & 0 \\
\hline $\mathrm{P} 1$ & 1 & 0 & 100 & 20 \\
\hline $\mathrm{P} 2$ & 2 & 0 & 100 & 0 \\
\hline P3 & 1 & 0,1 & 100 & 20 \\
\hline $\mathrm{P} 4$ & 2 & 0,1 & 100 & 0 \\
\hline P5 & 1 & 0,3 & 100 & 100 \\
\hline P6 & 2 & 0,3 & 100 & 20 \\
\hline P7 & 1 & 0,5 & 100 & 40 \\
\hline P8 & 2 & 0,5 & 100 & 0 \\
\hline
\end{tabular}

Keterangan: Angka 0 (nol) menunjukkan kalus tidak tumbuh

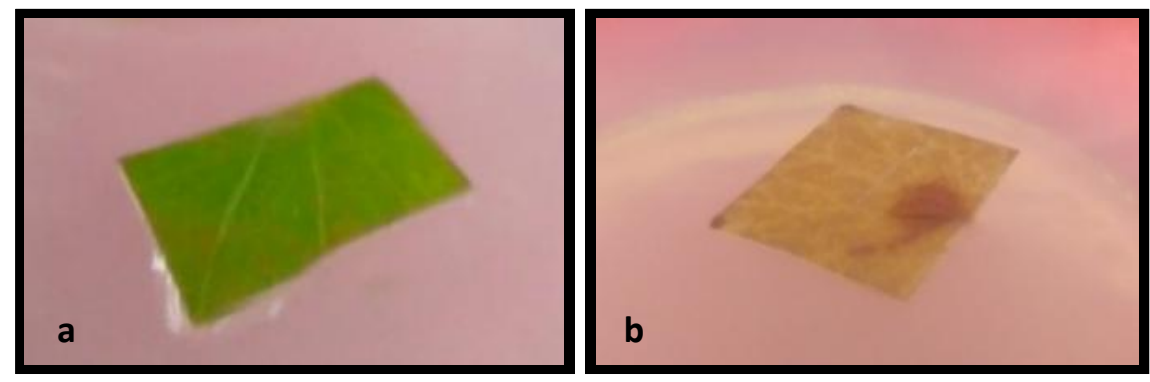

Gambar 1. Respons Eksplan Daun Pegagan pada Perlakuan P0 (Kontrol) : a) Eksplan segar pada perlakuan kontrol (0 HST); b) eksplan mati pada perlakuan kontrol (50 HST).

\section{Persentase Pembentukan Kalus}

Pembentuk kalus diawali dengan terjadi pembengkakan pada eksplan kemudian terdapat butiran seperti lendir/titik-titik air pada pelukaan. Pembentukan kalus pada eksplan I diawali dengan pembengkakan pada eksplan kemudian terdapat butiran seperti lendir/titik-titik air pada pelukaan eksplan (Basri 2008). Berdasarkan hasil penelitian, tidak semua perlakuan menghasilkan kalus, yaitu pada perlakuan P0 (kontrol), kalus tidak terbentuk dikarenakan medium kultur yang digunakan tanpa penambahan zat pengatur tumbuh sehingga hormon pertumbuhan endogen pada eksplan daun pegagan belum mampu menginduksi kalus. Hal ini sesuai dengan penelitian Kurniana (2017), bahwa tidak adanya zat pengatur tumbuh akan menyebabkan kalus atau organ tertentu tidak dapat tumbuh.

Eksplan daun pegagan yang menghasilkan kalus $100 \%$ hanya terdapat pada perlakuan P5 (1 mg/l BAP + 0,3 mg/l NAA). Kemungkinan konsentrasi zat pengatur tumbuh yang diformulasikan pada perlakuan P5 cukup efektif merangsang eksplan daun pegagan untuk membentuk kalus. Menurut Kaniyyah (2012) jika konsentrasi yang diberikan pada media mengalami keseimbangan maka akan terjadi interaksi antara kedua zat pengatur tumbuh tersebut dan akan merangsang terbentuknya kalus.

Pembentukan kalus pada eksplan daun pegagan diawali dengan pembengkakan eksplan dan diikuti dengan munculnya kalus pada pelukaan atau tepi eksplan. Pada Gambar 2.a. perlakuan P5 $(1 \mathrm{mg} / \mathrm{l} \mathrm{BAP}+0,3 \mathrm{mg} / \mathrm{l}$ NAA) eksplan mengalami pencoklatan pada pelukaan artinya eksplan merespon pemberian zat pengatur tumbuh pada media. Gambar 2.b. eksplan membengkak, selanjutnya terbentuk kalus pada bagian pelukaan eksplan (Gambar 2.c). Kalus terbentuk pada bagian pelukaan daun dikarenakan sebagai upaya perlindungan eksplan terhadap pelukaan yang berguna sebagai jaringan penutup luka pada eksplan Selanjutnya, kalus semakin banyak dan menutupi seluruh bagian permukaan eksplan (Gambar 2.d). 

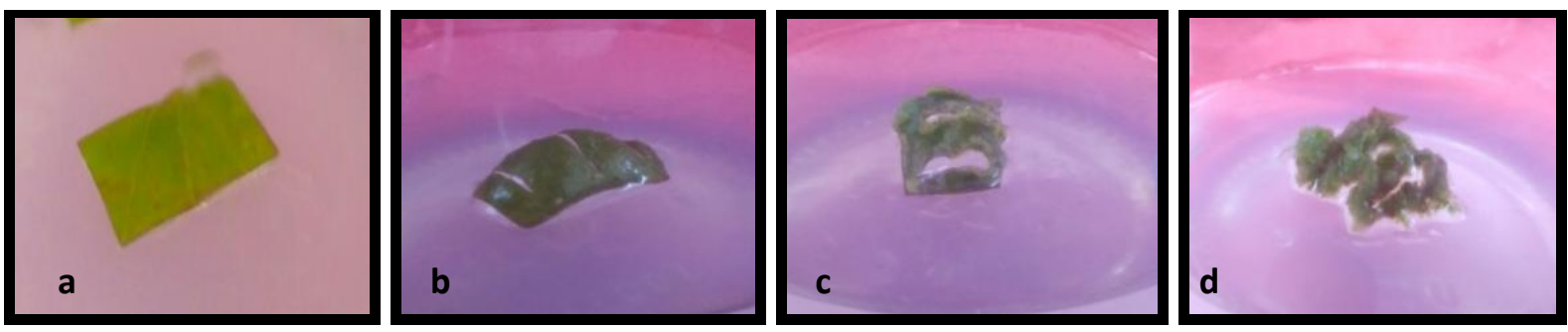

Gambar 2. Tahapan Pembentukan Kalus Eksplan Daun Pegagan pada Perlakuan P5 (1 mg/l BAP + 0,3 mg/l NAA) : a) Eksplan mengalami pencoklatan setelah inkubasi 3 HST; b) Eksplan mengalami pembengkakan (7 HST); c) Eksplan membentuk kalus pada pelukaan daun (18 HST); d) Kalus menutupi semua bagian permukaan eksplan daun (50 HST).

\section{Waktu Muncul Kalus}

Data pada Tabel 2 menunjukkan bahwa pada perlakuan yang membentuk kalus, tidak semua ulangannya dapat membentuk kalus juga. Seperti pada perlakuan P1 (1 mg/l BAP), P3 (1 mg/l BAP + 0,1 mg/l NAA), dan P6 (2 mg/l BAP + 0,3 mg/l NAA) hanya 1 (satu) ulangan saja yang membentuk kalus, sedangkan perlakuan P7 (1 mg/l BAP $+0,5$ $\mathrm{mg} / \mathrm{l}$ NAA) hanya 2 (dua) ulangan yang membentuk kalus. Hal ini dimungkinkan bahwa tidak semua eksplan pada perlakuan yang sama mampu memberikan respon yang sama pula. Sesuai dengan penelitian Sriskandarajah et al. (2006) menyatakan perbedaan respon eksplan pada penambahan auksin dan sitokinin dengan konsentrasi yang sama dalam meregenarasi kalus tergantung pada level hormon endogen yang terkandung dalam eksplan.

Tabel 2. Waktu Muncul Kalus (HST) pada Eksplan Daun Pegagan (Centella asiatica) dengan Perlakuan BAP Tunggal dan Kombinasi Penambahan BAP dan NAA selama 50 HST

\begin{tabular}{|c|c|c|c|c|c|c|c|}
\hline \multirow[t]{2}{*}{ Kode } & \multicolumn{2}{|c|}{ Perlakuan } & \multicolumn{5}{|c|}{ Ulangan } \\
\hline & BAP (mg/l) & NAA $(m g / l)$ & U1 & $\mathrm{U} 2$ & U3 & $\mathrm{U} 4$ & U5 \\
\hline $\mathrm{P} 0$ & $\overline{0}$ & $\overline{0}$ & - & - & - & - & - \\
\hline P1 & 1 & 0 & 18 & - & - & - & - \\
\hline P2 & 2 & 0 & - & - & - & - & - \\
\hline P3 & 1 & 0,1 & 18 & - & - & - & - \\
\hline P4 & 2 & 0,1 & - & - & - & - & - \\
\hline P5 & 1 & 0,3 & 18 & 18 & 18 & 18 & 18 \\
\hline P6 & 2 & 0,3 & 18 & - & - & - & - \\
\hline P7 & 1 & 0,5 & 18 & 42 & - & - & - \\
\hline P8 & 2 & 0,5 & - & - & - & - & - \\
\hline
\end{tabular}

Keterangan : Tanda negatif (-) menandakan kalus tidak tumbuh

\section{Warna Kalus}

Data hasil penelitian pada Tabel 3 menunjukkan bahwa warna kalus yang dihasilkan yaitu hijau dan coklat. Perbedaan warna kalus menunjukkan bahwa tingkat perkembangan kalus berbeda-beda. Pada perlakuan P5 (1 mg/l BAP + 0,3 mg/l NAA) merupakan kalus dengan warna hijau dapat dilihat pada Gambar 3.a. Warna kalus hijau menunjukkan bahwa kalus masih aktif membelah. Menurut Hanifah (2007), pada penambahan auksin dan sitokinin dengan konsentrasi yang tepat cenderung menunjukkan warna hijau (cerah) pada kalus lebih tahan lama. 
Nurhayati Anwar dkk.

Tabel 3. Morfologi Kalus dan Pertumbuhan Kalus Eksplan Daun Pegagan (Centella asiatica (L.) Urb.) dengan Perlakuan BAP Tunggal dan Kombinasi Penambahan BAP dan NAA selama 50 HST

\begin{tabular}{cccccc}
\hline Kode & \multicolumn{2}{c}{ Perlakuan } & Warna Kalus & Tekstur Kalus & Pertumbuhan Kalus \\
& BAP $(\mathrm{mg} / \mathrm{l})$ & NAA $(\mathrm{mg} / \mathrm{l})$ & & \\
\hline P0 & 0 & 0 & - & - & - \\
P1 & 1 & 0 & Coklat & Kompak & + \\
P2 & 2 & 0 & - & - & - \\
P3 & 1 & 0,1 & Coklat & Kompak & ++ \\
P4 & 2 & 0,1 & - & - & - \\
P5 & 1 & 0,3 & Hijau & Kompak & +++ \\
P6 & 2 & 0,3 & Coklat & Kompak & + \\
P7 & 1 & 0,5 & Coklat & Kompak & + \\
P8 & 2 & 0,5 & - & - & - \\
\hline
\end{tabular}

Keterangan: Tanda negatif (-) menunjukkan kalus tidak terbentuk, sedangkan tanda positif (+) menunjukkan kalus terbentuk

Gambar 3.b menunjukkan kalus berwarna coklat pada perlakuan P3 $(1 \mathrm{mg} / \mathrm{l}$ $\mathrm{BAP}+0,1 \mathrm{mg} / \mathrm{l} \mathrm{NAA})$. Peristiwa pencoklatan pada kalus merupakan suatu peristiwa alamiah yang sering terjadi dan sebagai respons bagi tanaman akibat adanya pengaruh fisik seperti pengupasan, pemotongan atau pelukaan. Selain menandakan terjadinya sintesis senyawa fenol, pencoklatan pada kalus diduga terjadi akibat bertambahnya umur sel atau jaringan kalus dan terlambatnya proses subkultur, sehingga eksplan menghasilkan senyawa fenol yang tinggi dan menjadi toksik bagi eksplan serta menyebabkan perubahan warna kalus menjadi coklat. Subkultur pada media baru dapat meminimalkan resiko toksik pada eksplan.

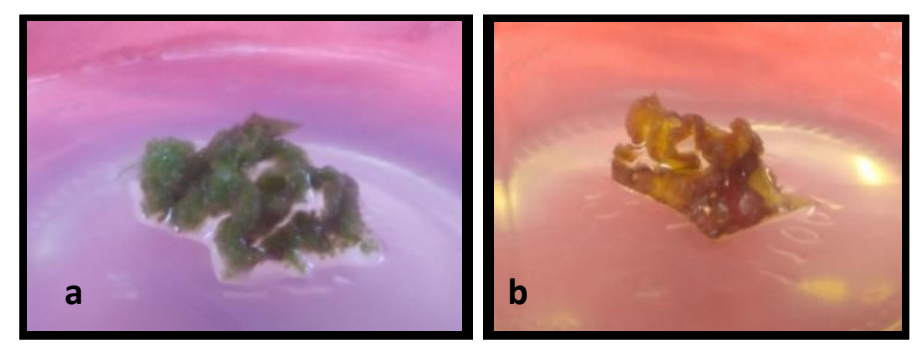

Gambar 3. Morfologi kalus eksplan daun pegagan setelah 50 HST : a) Kalus berwarna hijau dan kompak P5 (1 $\mathrm{mg} / \mathrm{l} \mathrm{BAP}+0,3 \mathrm{mg} / \mathrm{l} \mathrm{NAA})$; b) Kalus berwarna coklat dan kompak P3 (1 mg/l BAP + 0,1 mg/l NAA).

\section{Tekstur Kalus}

Data hasil penelitian pada Tabel 3 menunjukkan bahwa perlakuan P1 (1 mg/l BAP), P3 (1 mg/l BAP + 0,1 mg/l NAA), P5 (1 mg/l BAP + 0,3 mg/l NAA), P6 (2 mg/l $\mathrm{BAP}+0,3 \mathrm{mg} / \mathrm{l} \mathrm{NAA})$, dan P7 (1 mg/l BAP + $0,5 \mathrm{mg} / \mathrm{l} \mathrm{NAA})$ secara visual menghasilkan kalus dengan tekstur kompak. Kalus bertekstur kompak mempunyai susunan sel yang padat dengan dinding polisakarida yang lebih tebal sehingga sulit untuk dipisahkan. Menurut Silalahi (2015), eksplan yang dikulturkan pada media dengan penambahan BAP dan NAA cenderung akan membentuk kalus yang kompak dan padat.
Kalus yang baik dalam regenerasi tanaman diasumsikan memiliki tekstur remah, karena mudah dalam pemisahan menjadi selsel tunggal. Pada penelitian ini kalus yang didapatkan bertekstur kompak, sehingga untuk mendapatkan kalus dengan tekstur remah dapat dihasilkan melalui subkultur berulang-ulang pada perlakuan yang sama atau perlakuan yang berbeda.

\section{Pertumbuhan Kalus}

Pertumbuhan kalus (Tabel 3) yang paling tinggi $(+++)$ terdapat pada perlakuan P5 (1 mg/l BAP + 0,3 mg/l NAA) (Gambar 4.c. dan 4.d.), pertumbuhan kalus sedang $(++)$ pada perlakuan P3 (1 mg/l BAP + 0,1 mg/l NAA) 
(Gambar 4.b.), sedangkan pertumbuhan kalus paling sedikit (+) pada perlakuan P1 $(1 \mathrm{mg} / \mathrm{l}$ BAP), P6 (2 mg/l BAP + 0,3 mg/l NAA), dan P7 (1 mg/l BAP + 0,5 mg/l NAA) (Gambar 4.a.). Kondisi ini kemungkinan muncul karena penambahan zat pengatur tumbuh eksogen mampu berinteraksi dengan zat pengatur tumbuh endogen pada eksplan dan memberikan hasil yang berbeda-beda (Indah dan Ermavitalini 2013).
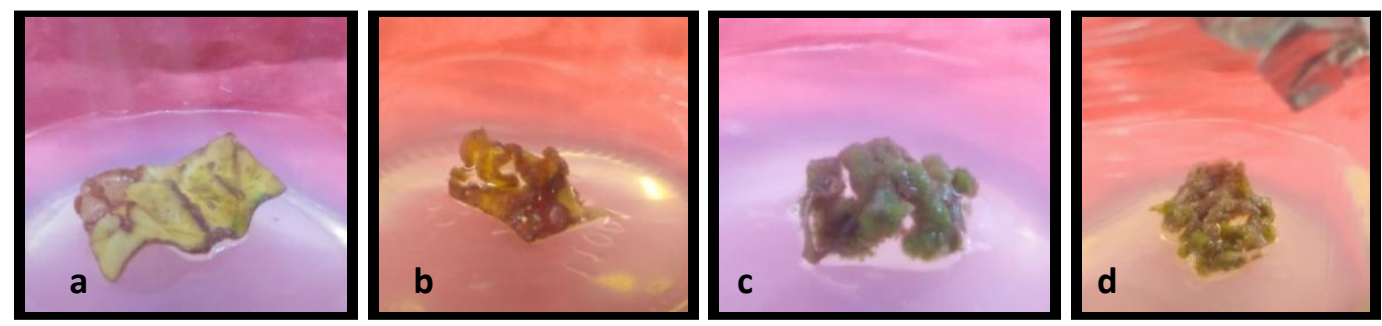

Gambar 4. Pertumbuhan kalus eksplan daun pegagan pada 50 HST : a) Kalus paling sedikit $(+)$ pada perlakuan P1 (1 mg/l BAP); b) Kalus sedang (++) pada perlakuan P3 (1 mg/l BAP + 0,1 mg/l NAA); c) dan (d) Kalus paling banyak (+++) terdapat pada perlakuan P5 ( $1 \mathrm{mg} / \mathrm{l} \mathrm{BAP} \mathrm{+} \mathrm{0,3} \mathrm{mg/l} \mathrm{NAA).}$

\section{Simpulan}

Pemberian perlakuan BAP tunggal dan kombinasi penambahan BAP dan NAA mampu memberikan respons berupa perubahan warna, pembengkakan eksplan dan pembentukan kalus pada semua perlakuan kecuali perlakuan kontrol. Konsentrasi terbaik untuk memacu pertumbuhan kalus eksplan daun pegagan yakni pada perlakuan P5 (1 mg/l $\mathrm{BAP}+0,3 \mathrm{mg} / \mathrm{l} \mathrm{NAA})$ dengan persentase terbentuk kalus $100 \%$ ditandai dengan warna kalus hijau, tekstur kalus kompak, dan pertumbuhan kalus yang tinggi $(+++)$.

\section{Daftar Pustaka}

Basri AHH. 2008. Kajian Pemanfaatan Kultur In Vitro dalam Perbanyakan Tanaman Bebas Virus. Agrica Ekstensia. 10 (1): 66.

Denish A. 2007. Percobaan Perbanyakan Vegetatif Kamaitan (Lunasia amara Blanco) melalui Kultur Jaringan. [Skripsi]. IPB. Bogor.

Fitrianti A. 2006. Efektivitas Asam 2,4Dikloropenoksiasetat (2,4-D) dan Kinetin pada Medium MS dalam Induksi Kalus Sambiloto dengan Eksplan Potongan Daun. [Skripsi]. Fakultas Matematika dan Ilmu Pengetahuan Alam UNS. Semarang.

Hanifah N. 2007. Pengaruh Konsentrasi NAA dan BAP terhadap Pertumbuhan Eksplan Jarak Pagar (Jatropha curcas L.) secara In Vitro. [Skripsi] Fakultas Pertanian UNS. Surakarta.
Indah PN \& D. Ermavitalini. 2013. Induksi Kalus Daun Nyamplung (Calophyllum inophyllum Linn.) pada Beberapa Kombinasi Konsentrasi 6-Benzyl Amino Purine (BAP) dan 2,4Diclorophenoxyacetic Acid (2,4-D). Jurnal Sains dan Seni Pomits. 2(1). 23373520 .

Khaniyyah S, N.A. Habibah, Sumadi. 2012. Pertumbuhan Kalus Daun Dewa (Gynura procumbens L. Merr) dengan Kombinasi 2,4-Dichlorophenoxyacetic Acid dan Kinetin secara In Vitro. Jurnal Biosantifika. 4 (2): 33-40.

Kurniana ROB. 2017. Pengaruh Variasi Zat Pengatur Tumbuh BAP dan NAA terhadap Pembentukan Organ, Kalus, dan Senyawa Aktif pada Daun Zodia (Evodia suavaolens Scheff.). [Skripsi]. Fakultas Farmasi Universitas Setia Budi. Surakarta.

Roy SK \& S. Raha. 1996. Clonal Propagation of Azadiractha indica by In Vitro Culture. Plant Tissue Culture Science Publisher. 149-54.

Silalahi M. 2015. Pengaruh Modifikasi Media Murashige-Skoog (MS) dan Zat Pengatur Tumbuh BAP terhadap Pertumbuhan Kalus Centella asiatica L. (Urban.). Jurnal Pro Life. 2(1): 14-23.

Sutardi. 2016. Kandungan Bahan Aktif Tanaman Pegagan dan Khasiatnya untuk Meningkatkan Sistem Imun Tubuh. Jurnal Libang Pertanian. 35(3): 121-130.

Sriskandarajah SE, V. Prise, P.I. Motyka, M. Dobrev, Serek. 2006. Regenerative Capacity of Cacti Schlumbergera and Rhipsalidopsis in Relatioan to 
Endogeneous Phytohormones, Cytokinin Oxidase and Peroxidase Activities. Journal Plant Growth Regul. 25: 79-88.

Wahyuningtiyas L, R.S Resmisari, Nashichuddin. 2014. Induksi Kalus Akasia (Acacia mangium) dengan Penambahan Kombinasi
2,4-D dan BAP pada Media MS. [Skripsi] Jurusan Biologi Fakultas Sains dan Teknologi. Jakarta.

Winarto WR, M. Surbakti. 2003. Khasiat dan Manfaat Pegagan (Centella asiatica L.). Jakarta: Agromedia Pustaka. 